\title{
Aplicação de geotecnologias para análise e interpretação dos focos de queimadas no município de São Raimundo das Mangabeiras/MA
}

As queimadas consistem em uma prática agrícola vastamente usada no Brasil e que causa inúmeros impactos ambientais, tais como o empobrecimento do solo e a perda da vegetação e da biodiversidade. Saber quais são as causas e onde as queimadas acontecem com maior intensidade é de extrema importância para a criação de planos de prevenção e combate ao fogo. Diante disso, o presente trabalho objetivou quantificar o número de focos de queimadas no Município de São Raimundo das Mangabeiras, Maranhão para o período de janeiro/2017 a janeiro/2018 - 1 ano. A metodologia baseou-se em levantamento de dados de focos de queimadas fornecidos pelo INPE (Instituto Nacional de Pesquisas Espaciais) e no uso de ferramentas de geoprocessamento e de SIG (Sistema de Informações Geográficas). Com a pesquisa notou-se que mais de 250 focos de queimadas foram registrados no período estudado, colocando o estado do Maranhão nos primeiros lugares do ranking de queimadas.

Palavras-chave: Impactos Ambientais; Vegetação; Queimadas.

\section{Application of geotechnologies for analysis and interpretation of burning focuses in the municipality of São Raimundo das Mangabeiras/MA}

\begin{abstract}
As burning is an agricultural practice widely used in Brazil and causing environmental damage, such as soil impoverishment and loss of vegetation and biodiversity. Find out what the causes are and where the fires occur with greater intensity and extreme importance for the creation of fire prevention and firefighting plans. Therefore, the present study aims to quantify the number of fires in the municipality of São Raimundo das Mangabeiras, in Maranhão, during the period from January/2017 to January/2018 - 1 year. A methodology based on the collection of data on fires foci applied by INPE (National Institute for Space Research) and the use of geoprocessing tools and GIS (Geographic Information System). With a survey that shows that more than 250 fires were recorded in the studied period, the display or state of Maranhão in the first places of the ranking of fires.
\end{abstract}

Keywords: Environmental Impacts; Vegetation; Burned.

Topic: Tecnologia, Modelagem e Geoprocessamentos

Reviewed anonymously in the process of blind peer.
Received: 08/09/2020

Approved: 07/11/2020
Jeferson Botelho Rodrigues (iD)

Universidade Vale do Rio Verde, Brasil

http://lattes.cnpq.br/9702846379230129

http://orcid.org/0000-0001-6371-7912

botelhojef@gmail.com

Stephanie Jael Negrão de Freitas

Universidade Federal do Pará, Brasil

http://lattes.cnpq.br/1432769722634758

http://orcid.org/0000-0001-9917-5342

negro.stephanie@gmail.com

Beatriz da Silva Alves (if

Universidade Estadual do Maranhão, Brasil

http://lattes.cnpq.br/9471479171047300

http://orcid.org/0000-0002-9643-4625

eng.beatrizalves@gmail.com

\author{
Jennifer da Cruz Arouche Silva (iD \\ Universidade Estadual do Maranhão, Brasil \\ http://lattes.cnpq.br/0091298366848905 \\ http://orcid.org/0000-0003-4910-3548 \\ jennifer.arouche@hotmail.com \\ Ketelly Marley Campos Cantanhede ic \\ Pontifícia Universidade Católica de Minas Gerais, Brasil \\ http://lattes.cnpq.br/1194756344409300 \\ http://orcid.org/0000-0002-9071-5370 \\ ketellycampos@gmail.com \\ Gleison Matheus Silva dos Santos (1D) \\ Faculdade Pitágoras de São Luís, Brasil \\ http://lattes.cnpq.br/1738110459928633 \\ http://orcid.org/0000-0003-3767-2946 \\ mathe.silvg@gmail.com
}

Referencing this:

RODRIGUES, J. B.; FREITAS, S. J. N.; ALVES, B. S.; SILVA, J. C. A.; CANTANHEDE, K. M. C.; SANTOS, G. M. S.. Aplicação de geotecnologias para análise e interpretação dos focos de queimadas no município de São Raimundo das Mangabeiras/MA. Nature and Conservation, v.13, n.4, p.123-127, 2020. DOI: http://doi.org/10.6008/CBPC23182881.2020.004.0014 


\section{INTRODUÇÃO}

O Maranhão é o estado com o maior número de queimadas no Nordeste, de acordo com dados do INPE em agosto de 2015 foram registrados no Brasil, 39.459 focos de queima, sendo 5.428 focos somente no Maranhão, classificando o Estado em 2ㅇ lugar no ranking nacional de queimadas para este mês (CEPDEC-MA, 2016). As queimadas consistem em uma prática agrícola antiga e vastamente usada no Brasil, diversos autores afirmam que a ocorrência de queimadas traz inúmeros impactos ambientais, como o empobrecimento do solo, a perda da biodiversidade de flora e fauna, efeitos no balanço radiativo da atmosfera e no clima em diferentes escalas, o uso inadequado das queimadas causa também grandes perdas econômicas como a destruição de propriedades privadas, interrupção do trafego aéreo, desligamento de redes elétricas. Além dos efeitos aos ecossistemas, os poluentes gerados pela queima de biomassa proporcionam efeitos deletérios à saúde humana (ARTAXO et al., 2005; GIGANTE et al., 2007; MÉLO et al., 2011).

Saber quais são as causas e onde as queimadas acontecem com maior intensidade é de extrema importância para a criação de planos de prevenção e combate ao fogo. De acordo com Fonseca et al. (2003) as atividades preventivas são mais eficientes quando baseadas em informações como em quais áreas o fogo surge com maior frequência e o que favoreceu o seu acontecimento nessas áreas.

Em vista disso, o objetivo deste estudo foi quantificar a ocorrência de queimadas no município de São Raimundo das Mangabeiras/MA para o período de janeiro de 2017 a janeiro de 2018 - 1 ano, tendo em vista a necessidade de conhecer a situação atual do município, sobre o problema em questão.

\section{MATERIAIS E MÉTODOS}

O Município de São Raimundo das Mangabeiras/MA está localizado na região Sul do Estado do Maranhão, como mostra a Figura 1, possui com uma população de aproximadamente 18.548 habitantes e extensão territorial de $3521,740 \mathrm{~km}^{2}$ (PNUD, 2013).

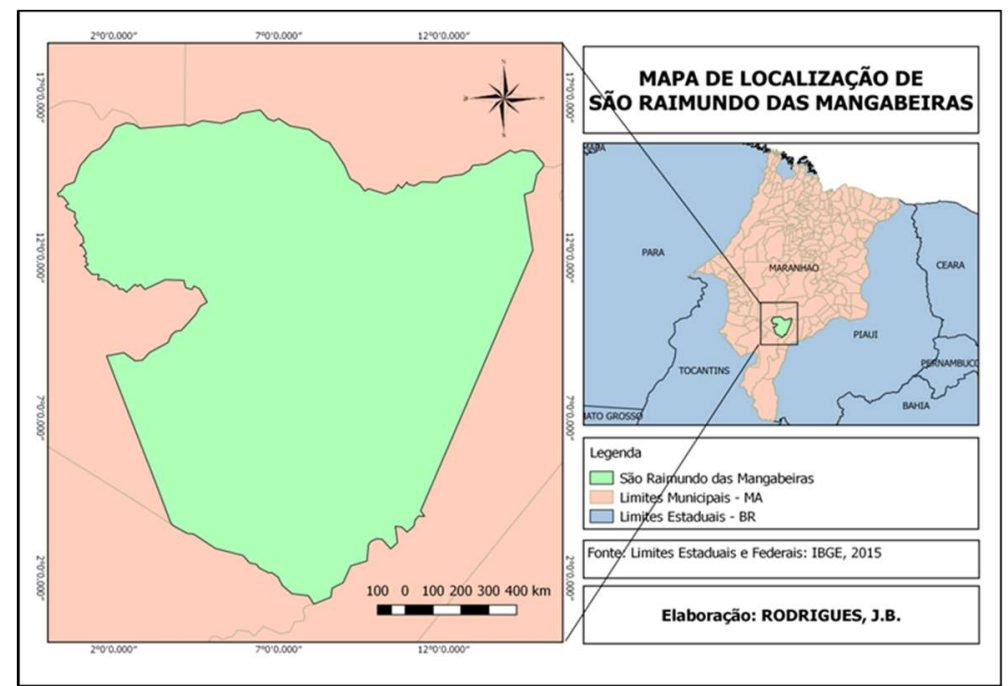

Figura 1: Mapa de localização do Município de São Raimundo das Mangabeiras/MA.

A cidade de São Raimundo das Mangabeiras a quase 800 km da capital do Maranhão, faz parte do 
bioma Cerrado com muita vegetação e possui clima tropical com um período de chuvas e estiagem bem definido, sendo os meses de setembro, outubro, novembro e dezembro característico como o período seco. Chove muito menos no inverno que no verão. O clima predominante é classificado como Subúmido $-\mathrm{C}_{2}$ de acordo com a Thornthwaite. $26.4{ }^{\circ} \mathrm{C}$ é a temperatura média em São Raimundo das Mangabeiras é $1190 \mathrm{~mm}$ é o valor da pluviosidade média anual.

Para a quantificação dos focos de queimadas no Município de São Raimundo das Mangabeiras/MA para o período de jan/2017 até jan/2018 - 1 ano - foi realizada uma revisão bibliográfica através dos dados de queimadas do INPE (Instituto Nacional de Pesquisas Espaciais). Estes dados foram analisados considerando os focos registrados apenas pelo Satélite AQUA MT, um dos satélites mais consistentes para estudos comparativos ao longo do tempo. Posteriormente, utilizou-se ferramentas de geoprocessamento, para tal foi construído um banco de dados em ambiente SIG (Sistema de Informações Geográficas) no software QGis versão 2.18. Por meio da consulta espacial de intersecção no SIG, foram determinados os focos de queimada, no município para o período estudado.

\section{RESULTADOS E DISCUSSÃO}

A quantidade de focos de queimadas (FC) registradas no município de São Raimundo das Mangabeiras/MA no período de 01/01/2017 até 01/01/2018 é apresentada na Tabela 1 e Figura 2.

Tabela 1: Focos de queimadas no Município de São Raimundo das Mangabeiras, para o período estudado.

\begin{tabular}{l|l}
\hline \hline MÊS/ANO & NÚMERO DE FOCOS \\
\hline \hline Janeiro/2017 & 0 \\
\hline Fevereiro/207 & 01 \\
\hline Março/207 & 02 \\
\hline Abril/2017 & 02 \\
\hline Maio/2017 & 0 \\
\hline Junho/2017 & 09 \\
\hline Julho/2017 & 06 \\
\hline Agosto/2017 & 21 \\
\hline Setembro/2017 & 151 \\
\hline Outubro/2017 & 61 \\
\hline Novembro/2017 & 06 \\
\hline Dezembro/2017 & 0 \\
\hline Janeiro/2018 & 0 \\
\hline TOTAL & 259 \\
\hline
\end{tabular}

Foram registrados um total de 259 focos de queimadas em São Raimundo das Mangabeiras no período estudado. Os maiores números de focos de queimadas foram registrados nos meses de junho a outubro de 2017, registrando $21,151,61$, focos respectivamente, em geral a ocorrência de focos de queimadas, em especial nesses meses destacados, pode estar associada com vários fatores, como a quantidade de chuva que teve nesses meses ou o aumento das atividades antrópicas, por exemplo.

No Maranhão o período de chuvas e estiagem é bem definido, sendo os meses de setembro, outubro, novembro e dezembro característico como o período seco (IMESC, 2016). Logo, observa-se que o maior número de ocorrência de focos foi registrado no período de estiagem.

Segundo Justino et al. (2002) a maior incidência de focos de calor ocorre no Brasil no período de 
junho a outubro, com os menores valores de precipitação na parte central do País. Nestas condições, parte da vegetação em seu ciclo fenológico tende a perder as folhas, diminuído então as taxas de evapotranspiração. Com a queda das folhas abre-se espaço para a penetração da radiação solar que seca ainda mais gravetos, galhos e folhas, aumentando a inflamabilidade da floresta.

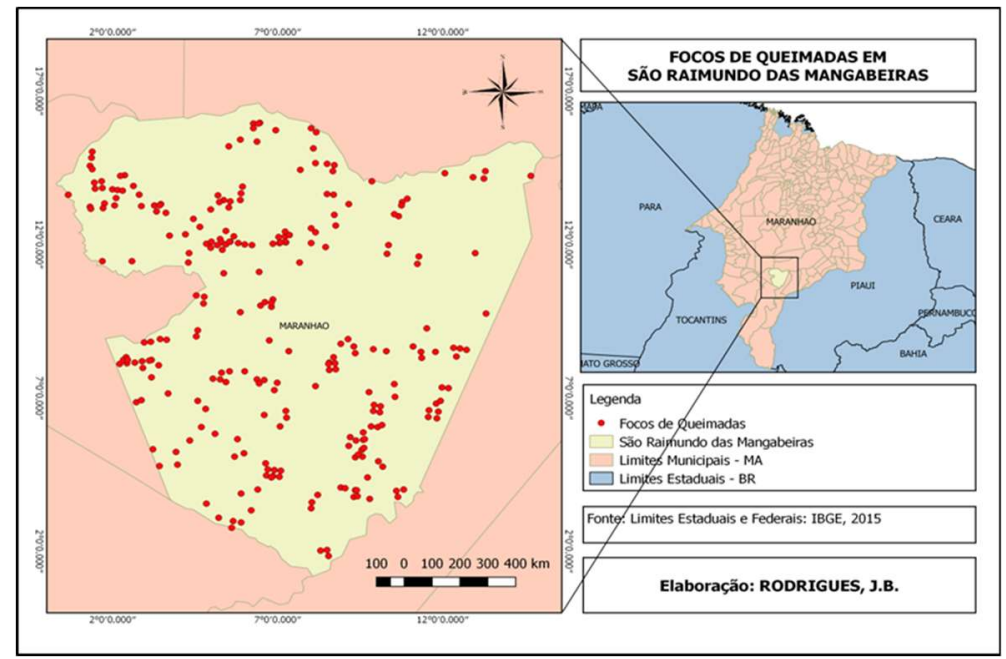

Figura 2: Focos de queimadas no município de São Raimundo das Mangabeiras/MA

Diante disso, nota-se que a dinâmica das queimadas no município de São Raimundo das Mangabeiras/MA parece estar alinhada com a sazonalidade climática e a sua variação regional. Todavia, vale ressaltar que apesar das condições atmosféricas serem fator determinante para queimadas, quem deflagra são as pessoas. Segundo Ramos (2011) pesquisadores do INPE confirmaram que 99\% das queimadas são provocadas pelo homem e que as condições atmosféricas favorecem os incêndios, mas as principais causas são econômicas e culturais. Alguns autores (TORRES et al., 2011; RAMOS et al., 2011) provaram que os focos de calor apresentam alta correlação com o desmatamento, estando diretamente relacionado com o uso do solo. Quanto ao município estudado, estudos realizados recentemente mostram que os focos de queimadas estão intimamente ligados com uso alternativo do solo (pastagens, agroindústrias e madeireiras), que desmata um grande percentual de área para essas atividades.

De acordo com a análise realizada pelo Plano de Ação para a Prevenção e o Controle do Desmatamento e das Queimadas no Estado do Maranhão (PPCD-MA) em 2011, acerca do desmatamento acumulado no Estado do Maranhão até 2009, demonstra que 43\% da área monitorada já tiveram a vegetação nativa convertida em outros usos do solo. No ano 2016 foram identificados 20.733 focos de queimadas pelo INPE (SILVA et al., 2017). São Raimundo das Mangabeiras está na lista dos municípios do Maranhão com maior área de desmatamento no bioma Cerrado, no período de 2009 a 2010, estando em primeiro lugar (IBAMA/MMA, 2011, citado por PPCD-MA, 2011).

O desmatamento causa desequilíbrios climáticos em razão da ausência das florestas que tinham como função gerar mais umidade do ar e absorver o calor atmosférico, desencadeando assim fenômenos como as queimadas. De acordo com pesquisa realizada entre os anos de 2008 a 2012, o aumento de 346\% de focos de queimadas no Estado do Maranhão registado no período do estudo está relacionado com o crescimento do setor agropecuário no Estado. 
Por fim, vale ressaltar que, os números registrados nesta pesquisa são muito alarmantes e preocupantes, pois as queimadas trazem consigo prejuízos em vários ecossistemas nos âmbitos econômicos, ambientais e afeta também a saúde da população. Essa problemática observada claramente configura-se como um obstáculo ao 'progresso local', posto que são itens básicos necessários para que se atinja uma sadia qualidade de vida.

\section{CONCLUSÕES}

Foram registrados no município de São Raimundo das Mangabeiras/MA um total de 259 focos de queimadas no período estudado. Os maiores números de focos de queimadas foram registrados nos meses de agosto, setembro e outubro de 2017. Políticas que incluem o combate ao desmatamento devem sempre estar aliadas às políticas de prevenção e combate às queimadas e aos incêndios florestais.

A maior parte dos focos de queimadas é causada por atividades humanas resultante de uma cultura habituada com a prática arcaica de atear fogo para limpar terrenos e abrir pastagens e áreas agricultáveis. As condições secas aumentam a susceptibilidade à queima, porém quem deflagra são as pessoas. Portanto, a situação observada de focos de queimadas em S pode ser atribuída à susceptibilidade decorrente clima seco prolongado, mas principalmente devido às ações de queimas criminosas, principalmente aquelas relacionadas ao desmatamento e ao avanço da fronteira agrícola, visto que é um município que a plantação de soja cresce cada dia mais.

\section{REFERÊNCIAS}

PNUD. Programa das Nações Unidas para o Desenvolvimento. Atlas do Desenvolvimento Humano no Brasil 2013. ATLAS BRASIL, 2013.

ARTAXO, P.; GATTI, V. L.; CÓRDOVA, M. A.; LONGO, M. K.; FREITAS, R. S.. Química atmosférica na Amazônia: A floresta e as emissões de queimadas controlando a composição da atmosfera amazônica. Acta Amazônica, v.35, p.185-196, 2005.

CEPDEC-MA. Coordenadoria Estadual de Proteção e Defesa Civil. Relatório de Monitoramento e Ações Contra Incêndios Florestais No Maranhão. São Luís: Estado do Maranhão, 2016.

FONSECA, E. M. B; RIBEIRO, G. A.. Manual de Prevenção de Incêndios Florestais. Belo Horizonte: CEMIG, 2003.

GIGANTE, L. A.; ZAVALA, R. Z.; PEREIRA, B. D.; SILVA, G. R.; OYAMADA, C. O.. Um estudo da similaridade das queimadas entre municípios no Estado de Mato Grosso. In: CONGRESSO DA SOCIEDADE BRASILEIRA DE ECONOMIA, ADMINISTRAÇÃO E SOCIOLOGIA RURAL, 45. Anais. Londrina: 2007.

IMESC. Instituto Maranhense de Estudos Socioeconômicos e Cartográficos. Análise da seca e estiagem maranhense. IMESC, 2016.

JUSTINO, F. B.; SOUZA, S. S.; SETZER, A.. Relação entre "focos de calor" e condições meteorológicas no Brasil. In:
CONGRESSO BRASILEIRO DE METEOROLOGIA, 12. Anais. Foz de Iguaçu, 2002.

MÉLO, A. S.; JUSTINO, F.; LEMOS, C. F.; SEDIYAMA, G.; RIBEIRO, G.. Suscetibilidade do ambiente a ocorrências de queimadas sob condições climáticas atuais e de futuro aquecimento global. Revista Brasileira de Meteorologia, v.26, n.3, p.401-418, 2011.

PPCD-MA. Plano de ação para a prevenção e o controle do desmatamento e das queimadas no estado do Maranhão. PPCD, 2011.

RAMOS, A. B. R.; NASCIMENTO, E. R. P.; OLIVEIRA, M. J. Temporada de incêndios florestais no Brasil em 2010: análise de série histórica de 2005 a 2010 e as influências das chuvas e do desmatamento na quantidade dos focos de calor. In: SIMPÓSIO BRASILEIRO DE SENSORIAMENTO REMOTO, 15. Anais. São José dos Campos: INPE, 2011.

SILVA, M.; TEREZA, A.; BEZERRA, D. S.; PEREIRA, L.; ELOI, C. M. A.; SANTOS, A. L. S.. A seca no Maranhão no período de 2010 a 2016 e seus impactos. Parceria Estratégicas, v.22, n.44, p.119-138, 2017.

TORRES, F. T. P.; RIBEIRO, G. A.; MARTINS, S. V.; LIMA, G. S.. Correlações entre os elementos meteorológicos e as ocorrências de incêndios florestais na área urbana de Juiz de Fora, MG. Revista Árvore, v.35, n.1, p.43-150, 2011.

A CBPC - Companhia Brasileira de Produção Científica (CNPJ: 11.221.422/0001-03) detém os direitos materiais desta publicação. Os direitos referem-se à publicação do trabalho em qualquer parte do mundo, incluindo os direitos às renovações, expansões e disseminações da contribuição, bem como outros direitos subsidiários. Todos os trabalhos publicados eletronicamente poderão posteriormente ser publicados em coletâneas impressas sob coordenação da Sustenere Publishing, da Companhia Brasileira de Produção Científica e seus parceiros autorizados. Os (as) autores (as) preservam os direitos autorais, mas não têm permissão para a publicação da contribuição em outro meio, impresso ou digital, em português ou em tradução. 